[2] Cieza A, Geyh S, Chatterji S, Kostanjsek N, Üstün B, Stucki G. ICF linking rules: An update based on lessons learned. J Rehabil Med. 2005;37 (4):212-218. doi:10.1080/16501970510040263.

Disclosure of Interests: None declared

DOI: 10.1136/annrheumdis-2019-eular.3524

\section{AB1346 PATIENTS‘ BELIEFS ABOUT MEDICINES PRESCRIBED FOR THEIR RHEUMATOID ARTHRITIS OR SPONDYLOARTHRITIS}

Nathalie Madeira, Candida Silva, Claudia Miguel, Dina Medeiros, Filipe Barcelos, Helena Santos, Ricardo Trinca, Alexandra Cardoso, Luís Cunha Miranda. Instituto Português de Reumatologia, Rheumatology, Lisbon, Portugal

Background: Adherence to therapies is determined by multiple factors, some of which are patient's related and include economic resources, knowledge, attitudes, beliefs, perceptions and expectations about medication.

Objectives: To assess patients' beliefs about prescribed medication for their rheumatic disease (rheumatoid arthritis (RA) or spondyloarthritis $(\mathrm{SpA})$, including psoriatic arthritis) and to determine the existence of any association between these beliefs and clinical and socio-demographic variables.

Methods: Observational cross-sectional study which included RA patients according to 1987 ACR and/or 2010 ACR/EULAR criteria and SpA patients according to 2009 ASAS classification criteria (CC) for axial SpA or to 2011 ASAS CC for peripheral SpA, on subcutaneous biological therapy, followed at our Center, able to complete questionnaires autonomously and who agreed to participate. Socio-demographic and clinical data, anxiety and depression through the Hospital Anxiety and Depression Scale (HADS) and fatigue using the Functional Assessment of Chronic IIIness Therapy - Fatigue questionnaire (FACIT-F) were collected. To assess beliefs about medication, the cross-culturally adapted Portuguese version of the Beliefs about Medicines Questionnaire (BMQ)-Specific was used, asking patients to apply it considering only the prescribed medicines for AR or SpA. The BMQ-Specific comprises two subscales: a fiveitem Necessity scale (Specific-Necessity, SN) and a six-item Concerns scale (Specific-Concerns, SC). Each item is scored on a five-point Likert scale (from $1=$ strongly disagree to $5=$ strongly agree). Statistics: descriptive, Mann-Whitney and Kruskal-Wallis tests and Spearman correlation, $\mathrm{p}<0.05$.

\begin{tabular}{lcc}
\hline & RA patients & SpA patients \\
\hline Current age - years & Median (IQR) & Median (IQR) \\
& $60,0(51,0-$ & $47,0(39,5-$ \\
Disease duration - years & $66,0)$ & $57,0)$ \\
& $14,5(12,0-$ & $13,0(8,0-$ \\
Time on treatment with the current biologic therapy - & $18,3)$ & $19,0)$ \\
months & $31,0(20,0-$ & $37,0(12,0-$ \\
PGA & $62,0)$ & $83,0)$ \\
& $32,0(6,0-$ & $29,0(14,5-$ \\
VAS pain & $55,0)$ & $51,5)$ \\
& $41,0(21.0-$ & - \\
PhGA & $60.0)$ & $12,5(5,0-$ \\
& $19,5(6,5-$ & $23,5)$ \\
Nocturnal back pain VAS & $33,8)$ & $17,0(4,5-$ \\
& - & $34,0)$ \\
Back pain VAS & & $18,0(5.5-$ \\
& - & $43,0)$ \\
VS - mm/H & $15,0(7,0-$ & $7,0(2,0-14,0)$ \\
& $30,5)$ & \\
CRP - mg/dL & $0,2(0,1-0,6)$ & $0,3(0,1-1,0)$ \\
DAS28_4V & $3,2(2,4-4,4)$ & - \\
BASDAI & - & $2,8(1,1-4,6)$ \\
ASDAS & - & $1,8(1,1-2,4)$ \\
BASMI & - & $2,7(2,1-4,0)$ \\
HAQ & $18,0(15,0-$ & $18,0(13,5-$ \\
BASFI & $22,0)$ & $22,0)$ \\
BMQ-SN & & - \\
BMQ-SC & - & $1,8(0,7-3,7)$ \\
\hline
\end{tabular}

Abstract AB1346 Table 1. Descriptive statistics of the continuous variables of the RA and SpA patients

Results: We obtained data from 84 patients, $45 \mathrm{SpA}$ (53.6\%) and 39 (46.4\%) RA patients. Table 1 presents the descriptive statistics of the continuous variables. In RA group, 92.3\% were female, $84.6 \%$ under antiTNF, $66.7 \%$ under their 1st biologic and we found an association between BMQ-SC score and HADS-anxiety $(p=0.013)$ and positive correlations between BMQ-SC score and Patient Global Assessment (PGA) $(p=0.031)$, VAS pain $(p=0.004)$, Physician's Global Assessment (PhGA) $(p=0.004)$, DAS28 $(p=0.007)$, and HAQ ( $p<0.001)$. In SpA group, 62.2\% were female, $86.7 \%$ under anti-TNF, $77.8 \%$ under their 1st biologic and BMQ-SN score was positively correlated with VAS nocturnal back pain $(p=0.047)$, PhGA $(p=0.045)$ and BASFI $(p=0.003)$.

Conclusion: In RA patients, those with higher disability and a clinically more active disease presented higher levels of concern regarding the medication. In SpA, patients with a more aggressive disease, with nocturnal pain and worse function have a stronger conviction of the necessity and efficacy of the medication.

\section{REFERENCES}

[1] Salgado T, Marques A, Geraldes L, Benrimoj S. Horne R. Fernandes-Llimos F. Cross-cultural adaptation of the Beliefs about Medicines Questionnaire into Portuguese. Sao Paulo Med J. 2013; 131(2):88-94. doi:10.1590/ S1516-31802013000100018.

Disclosure of Interests: Nathalie Madeira: None declared, Candida Silva: None declared, Claudia Miguel: None declared, Dina Medeiros: None declared, Filipe Barcelos Consultant for: Pfizer; Ely-Lilly, Speakers bureau: Novartis, Helena Santos: None declared, Ricardo Trinca: None declared, Alexandra Cardoso: None declared, Luís Cunha Miranda: None declared DOI: 10.1136/annrheumdis-2019-eular.3502

\section{AB1347 ASSESSMENT OF PATIENTS‘ KNOWLEDGE ABOUT BIOLOGIC THERAPY AS A SELF-COMPLETION QUESTIONNAIRE. IS IT A GOOD WAY TO DO IT?}

Nathalie Madeira, Candida Silva, Claudia Miguel, Dina Medeiros, Filipe Barcelos, Helena Santos, Ricardo Trinca, Alexandra Cardoso, Luís Cunha Miranda. Instituto Português de Reumatologia, Rheumatology, Lisbon, Portugal

Background: Lack of knowledge from a patient in his therapy may lead to a misuse process, increasing the probability of failure to achieve the therapeutic goal.

Objectives: To evaluate if the assessment of the RA and SpA patients' knowledge in their biologic therapy could be done as a self-completion questionnaire.

Methods: Observational cross-sectional study which included patients with RA according to 1987 ACR and/or 2010 ACR/EULAR criteria or SpA according to 2009 ASAS classification criteria (CC) for axial SpA or to 2011 ASAS CC for peripheral SpA (including patients with psoriatic arthritis), on subcutaneous biological therapy who agreed to participate. Patients' knowledge about their biologic therapy was assessed using the "Conhecimento do doente sobre os seus medicamentos" (CPM-PT-PT), meaning "Patient's knowledge about his medicines", intercultural adaptation for the Portuguese version of the original Spanish questionnaire, CPMES-ES. This questionnaire was created to be used as an interview, but we decided to give it to patients and ask them to complete it autonomously, reading the questions and writing their answers, considering only their biologic therapy. It consists of 11 questions, each with a score based on patient's answer: incorrect $=-1$, the patient doesn't know $=0$, incomplete $=1$ and correct $=2$. The final score is calculated using the mathematical formula described by the authors, ranging from 0 (doesn't know the medicine) to 2 points (optimal knowledge). Statistics: descriptive, Mann-Whitney and Kruskal-Wallis tests and Spearman correlation, $p$ $<0.05$.

Results: We included 84 patients, 45 of which with SpA $(53.6 \%)$ and 39 (46.4\%) with RA. In the RA group, $92.3 \%$ were female, $84.6 \%$ were under anti-TNF $\alpha, 66.7 \%$ were under their 1st biologic, the median age was $60.0(51.0-66.0)$ years and the median time in treatment with current biologic was $31.0(20.0-62.0)$ months. In the SpA group, 62.2\% were female, $86.7 \%$ were under anti-TNF, $77.8 \%$ were under their 1 st biologic, median age was $47.0(39.5-57.0)$ years and median time in treatment with current biologic was 37.0 (12.0-83.0) months. Fifteen incomplete questionnaires were excluded. Sixty patients $(87.0 \%$ of the 69 valid questionnaires) didn't meet the minimum criteria necessary to ensure correct use of medication (correct answer to the first 5 questions), thus obtaining a CPM score of 0 . The mean CPM score was $0.2 \pm 0.5$, the median 0 (0), the minimum 0 and the maximum 1,7. There were no differences in CPM according to age, time in treatment with the current biologic, disease duration, $\mathrm{n}^{\circ}$ of previous biologics, gender, educational level, diagnosis, current biologic and $\mathrm{n}^{\circ}$ of other concomitant drugs. Table 1 